\title{
A minimally-invasive method for sampling human petrous bones from the cranial base for ancient DNA analysis
}

Kendra A. Sirak ${ }^{1,2}$, Daniel M. Fernandes²,3, Olivia Cheronet², Mario Novak ${ }^{4}$, Beatriz Gamarra², Tímea Balassa ${ }^{5}$, Zsolt Bernert ${ }^{6}$, Andrea Cséki ${ }^{7}$, János Dani ${ }^{8}$, József Zsolt Gallina ${ }^{9}$, Gábor Kocsis-Buruzs ${ }^{10}$, Ivett Kővári11, Orsolya László ${ }^{12}$, Ildikó Pap ${ }^{6}$, Róbert Patay ${ }^{13}$, Zsolt Petkes $^{14}$, Gergely Szenthe ${ }^{15}$, Tamás Szeniczey ${ }^{16}$, Tamás Hajdu ${ }^{16}$, and Ron Pinhasi ${ }^{2,17}$ ${ }^{1}$ Department of Anthropology, Emory University, Atlanta, GA, USA 2 School of Archaeology and Earth Institute, Belfield, University College Dublin, Ireland, ${ }^{3} \mathrm{CIAS}$, Department of Life Sciences, University of Coimbra, Coimbra, Portugal, ${ }^{4}$ Institute for Anthropological Research, Zagreb, Croatia, ${ }^{5}$ Biomedical Centrum Ltd., Pomáz, Hungary, ${ }^{6}$ Hungarian Natural History Museum, Department of Anthropology, Budapest, Hungary, ${ }^{7}$ Archeodata 1998 Ltd., Polgár, Hungary, ${ }^{8}$ Déri Museum, Debrecen, Hungary, ${ }^{9}$ Ásatárs Ltd., Kecskemét, Hungary, ${ }^{10}$ Salisbury Ltd., Budaörs, Hungary, ${ }^{11}$ Defense POW/MIA Accounting Agency (DPAA), HI, USA ${ }^{12}$ Hungarian National Museum, Analytical Laboratory, Budapest, Hungary, ${ }^{13}$ Ferenczy Museum Center, Department of Archaeology, Szentendre, Hungary, ${ }^{14}$ Hungarian Academy of Sciences, Research Centre for the Humanities, Institute of History, Budapest, Hungary, ${ }^{15}$ Hungarian National Museum, Department of Archaeology, Budapest, Hungary, ${ }^{16}$ Eötvös Loránd University, Institute of Biology, Department of Biological Anthropology, Budapest, Hungary, and ${ }^{17}$ Department of Anthropology, University of Vienna, Vienna, Austria

BioTechniques 62:283-289 (June 2017) doi 10.2144/000114558

Keywords: cranial base drilling method, petrous bone, ancient DNA, preservation of skeletal remains

Supplementary material for this article is available at www.BioTechniques.com/article/114558.

Ancient DNA (aDNA) research involves invasive and destructive sampling procedures that are often incompatible with anthropological, anatomical, and bioarcheological analyses requiring intact skeletal remains. The osseous labyrinth inside the petrous bone has been shown to yield higher amounts of endogenous DNA than any other skeletal element; however, accessing this labyrinth in cases of a complete or reconstructed skull involves causing major structural damage to the cranial vault or base. Here, we describe a novel cranial base drilling method (CBDM) for accessing the osseous labyrinth from the cranial base that prevents damaging the surrounding cranial features, making it highly complementary to morphological analyses. We assessed this method by comparing the aDNA results from one petrous bone processed using our novel method to its pair, which was processed using established protocols for sampling disarticulated petrous bones. We show a decrease in endogenous DNA and molecular copy numbers when the drilling method is used; however, we also show that this method produces more endogenous DNA and higher copy numbers than any postcranial bone. Our results demonstrate that this minimallyinvasive method reduces the loss of genetic data associated with the use of other skeletal elements and enables the combined craniometric and genetic study of individuals with archeological, cultural, and evolutionary value.

Ancient DNA (aDNA) genome-wide analyses have provided major insights about genetic structure in past populations, detailed population movements and admixture events, revealed phenotypic variation, and provided evidence of selection (1-7). Next- generation sequencing (NGS) has led to significantly lower sequencing costs and improved sequencing output, opening doors to the massively parallel production of genetic data from ancient individuals (8). In the last 3 years, NGS has led to a 100-fold increase in the number of ancient human specimens analyzed as well as the magnitude and coverage of the genomic data obtained $(9,10)$. Additional recent developments in aDNA analysis have focused on increasing DNA yields through optimized extraction

\section{METHOD SUMMARY}

Here, we describe a minimally-invasive cranial base drilling method (CBDM) for accessing the DNA-dense osseous labyrinth of the petrous part of the temporal bone from the basal region of a complete skull without causing damage to anthropologically important cranial features. 
Table 1. Selected samples and skeletal elements.

\begin{tabular}{|c|c|c|c|c|c|}
\hline \multirow[t]{2}{*}{ Site } & \multirow[t]{2}{*}{ Burial Number } & \multirow[t]{2}{*}{ Sample Name } & \multicolumn{2}{|c|}{ Processing of petrous } & \multirow[t]{2}{*}{ Postcranial element } \\
\hline & & & Right & Left & \\
\hline Balatonendréd-Vaklápa Öreghegy & $36 / 48 / 2013.1 .2$ & BALA36/48 & CBDM: cochlea / SCCs & Collected & Fibula shaft \\
\hline Balatonendréd-Vaklápa Öreghegy & $118 / 201 / 2013.1 .16$ & BALA118/201 & Collected & CBDM: cochlea / SCCs & Left femur shaft \\
\hline Ecser & $223 / 2008.2 .2$ & Ecser223 & Collected & CBDM: cochlea & Right femur shaft \\
\hline Ecser & $3318 / 2008.2 .19$ & Ecser3318 & CBDM: cochlea & Collected & Right femur shaft \\
\hline Ófehértó Almezői-dűlő & $194 / 442$ & OFE194/442 & Collected & CBDM: cochlea / SCCs & Left fibula shaft \\
\hline Ófehértó Almezői-dűlő & $194 / 443$ & OFE194/443 & CBDM: cochlea & Collected & Right $2^{\text {nd }}$ metacarpal \\
\hline Kiskunfélegyháza-Lidl & 204 & KIS204 & CBDM: cochlea & Collected & Right femur shaft \\
\hline
\end{tabular}

protocols (11), improved library preparation $(12,13)$, and the addition of enrichment techniques prior to sequencing $(14,15)$. These developments have led to the first publications of genome-wide data on prehistoric human specimens from non-temperate regions, including Africa, the Near East, and the Southwest Pacific (2,7,16-19). Nevertheless, an equally important potential area of improvement is bone sampling methods. This includes establishing which skeletal elements are most amenable for aDNA analysis $(20,21)$ and how to prepare a bone sample for optimal DNA retrieval $(22,23)$.

A significant advance in aDNA analysis was the targeting of the petrous part of the temporal bone (pars petrosa ossis temporalis, located between the sphenoid and occipital bones at the base of the skull and housing the organs of hearing and balance) as the preferred region for aDNA sampling. While petrous bone is just one of several substrates, including tooth cementum (21) and hair (24), demonstrated to be superior for DNA preservation, human petrous bones have yielded up to 183-fold more DNA than any other skeletal element tested (rib, tooth, or long bone) (20) and have been shown to perform better overall than tooth cementum (21). A subsequent study of various regions within the petrous bone determined that the DNA-dense osseous labyrinth ("inner ear") yields up to 64-fold more endogenous DNA than the cortical bone encircling it, up to 177-fold more than trabecular bone from the apex of the petrous bone, and up to 410 -fold more than a corresponding metatarsal bone (25). The osseous labyrinth-including the cochlea, vestibule, and three semi-circular canals (26) - is known to be the hardest and densest bone in the mammalian body and has been shown to exhibit inhibited bone remodeling (27-29), likely contributing to its success in preserving DNA. Because many ancient samples contain low percentages of endogenous DNA ( $<1 \%)$, accessing the osseous labyrinth is crucial for obtaining optimal aDNA samples for any given specimen. However, it remains extremely difficult to obtain a bone sample from the osseous labyrinth in an intact skull without causing substantial damage to the skull. Thus, for complete skulls, a postcranial element is often used at the cost of a considerable reduction in data quality and quantity.

The petrous portion of the temporal bone is located inside the cranial vault and cannot be accessed through the foramen magnum at the cranial base, the only available opening. Thus, in the case of any complete or reconstructed cranium, accessing the petrous requires the disarticulation of the temporal bone from the rest of the skull, a particularly damaging process accomplished either by the complete breakage of the cranial vault or the removal of the temporal bone using a cutting tool. This type and extent of damage is often not permissible, particularly in the case of skeletal material collected for anthropological study, as it interferes with accurate analysis of cranial morphology. Moreover, the removal of the temporal bone or the obliteration of the structure of the cranial vault has a major negative impact on the ability to demarcate a number of craniometric landmarks used for determining patterns of human craniometric diversity, assessing selection pressures, and estimating biological affinities in ancient populations (30). Because craniometric studies depend on relatively complete skulls, many skulls were never sampled for genetic analysis. This has resulted in a decrease in sample size or even the complete exclusion of particular ancient populations for which skeletal remains are scarce.

Here, we report and evaluate a cranial base drilling method (CBDM) protocol for accessing the osseous labyrinth that minimizes damage to complete and reconstructed crania and prevents the obliteration of essential craniometric landmarks, making it highly complementary to anthropological analyses. To explore the efficacy of the CBDM in comparison to more destructive bone processing conducted in an aDNA cleanroom, we selected pairs of left/right petrous bones from the same skull and processed one side using the standard, destructive method in a cleanroom and the other using the CBDM on-site in the collections where the specimens were kept. For additional comparison, we also processed one corresponding postcranial element in a cleanroom. We then sequenced the DNA retrieved from these specimens to compare the genetic data obtained from the various skeletal elements processed using each technique. Comparing results for each petrous pair, one processed with the CBDM and the other processed in a cleanroom, we observed on average a small quantitative reduction in human reads (maximum 3.5-fold), endogenous DNA yield (maximum 2.1-fold), and human copy number (maximum 19.3-fold) associated with use of the CBDM. However, the CBDM still provides substantially higher endogenous yields and copy number than any corresponding postcranial element tested. We also observed consistency between the data obtained from the CBDM and that obtained from cleanroomprocessed petrous bones. Based on these results, we determine that the CBDM provides a technique for obtaining high endogenous yields and complexity that are of a similar order of magnitude as produced by cleanroom processing of fragmentary petrous bones, while also minimizing major damage to important anatomical and landmark regions of the cranium. As such, it provides a method for obtaining robust genomic data from complete crania in a way that is complementary to various anthropological analyses.

\section{Materials and methods}

The CBDM protocol and details of extraction, library preparation, sequencing, and data analysis are provided in the Supplementary Material. 


\section{Sample selection}

We selected seven skeletal specimens with intact left and right petrous bones and corresponding postcranial elements, allowing us to directly compare the genetic data obtained from petrous samples drilled on-site using the CBDM to (i) the paired petrous bone and (ii) a postcranial element; samples from both (i) and (ii) were processed in an aDNA-dedicated cleanroom. Hungarian specimens ranging from the Late Neolithic (ca. 4900-4500 BC) to the Late Avar Period (ca. $8^{\text {th }}-9^{\text {th }}$ centuries AD) were chosen for this analysis (Supplementary Table S1). Based on previous analyses of prehistoric specimens from eastern Hungary (9), these samples were expected to have adequate DNA preservation that would enable us to detect variations resulting from differences in bone-processing methodologies and, at the same time, assess variations in aDNA yield across a period spanning nearly six millennia.

For each specimen, we randomly chose one petrous bone on which to perform the CBDM, while the paired petrous bone was collected whole and processed using a sandblaster in a cleanroom. The sandblaster allowed us to expose and isolate the osseous labyrinth in a controlled environment, but required the destruction of the majority of the petrous bone. We also collected one element from each of the corresponding postcranial skeletons (either a fragment of long bone shaft or metacarpal) and selected a dense region of the bone with no macroscopic evidence of degradation or damage, to be processed in our cleanroom. The skeletal elements selected from each sample are summarized in Table 1.

\section{Cranial base drilling}

The petrous pyramid is located inside the skull and also forms part of the external cranial base. Though the petrous part is visible from the cranial base, the osseous labyrinth is positioned deep within the petrous bone and cannot be directly accessed without the removal of some layers of bone. Using the CBDM, we obtained bone powder directly from the osseous labyrinth while minimizing damage to the structure of the complete skull by entering it at the site of the bony ridge separating the jugular foramen from the carotid canal on the basal surface of the skull (Figure 1).

To access the osseous labyrinth, we first reduced the bony ridge by grinding it with a 4.8-mm engraving cutter burr attached to a Dremel 9100-21 Fortiflex 2.5-Amp Stationary Flex Shaft Precision Rotary Tool (Dremel, Mount Prospect, IL) that is designed to produce high torque at low speeds. We controlled the speed of the rotary tool with a variable speed foot pedal and aimed to keep the speed as low as possible while still removing the ridge. The reduction of this ridge eventually revealed the hard and rounded inferior border of the cochlea. We then applied additional pressure while grinding to create a small opening into the osseous labyrinth. This opening appeared as a small hole in the center of the spherical border of the cochlea (Figure 2). We placed a $3.2 \mathrm{~mm}$ engraving cutting burr into this opening and moved it in a circular motion while applying pressure to obtain a fine-textured bone powder. The powder was collected in a standard disposable weigh boat that had been sterilized with a 10\% bleach solution and placed under the skull. We collected approximately 200-300 mg of bone powder, which was placed in a sterile Eppendorf tube for subsequent DNA extraction.

For each of the 7 ancient specimens, bone powder was collected from one petrous bone using the CBDM. In between the drilling of each specimen, the Dremel rotary tool, all grinding burrs and attachments, and the work areas were cleaned using a 10\% bleach solution and treated with ethanol. Gloves were changed between processing of each specimen to minimize cross-contamination.

DNA extraction and library preparation DNA was extracted from the bone powder collected from CBDM samples as well as from the petrous and postcranial bone samples processed using the sandblaster following the protocol from (11). Libraries for NGS were built for all extracts using a modified version of (31) and amplified through PCR. All extraction and library preparation steps took place in an aDNA laboratory physically separated from the cleanroom used for powdering bones in adherence with standard stringent anticontamination protocols. Negative controls were carried through all steps of sequencing preparation.

\section{Sequencing and data curation}

All libraries were sequenced on the Illumina NextSeq platform using a High Output v2 kit (75 cycles). Raw sequencing data were processed using a custom bioinformatics pipeline. The software cutadapt v.1.5 (32) was used to trim adapter sequences. Trimmed reads were aligned using the Burrows Wheeler Aligner v.0.7.5a-r405 (33) to the GRCh37 build of the human reference genome with the mitochondrial sequence replaced by the Cambridge reference sequence (NCBI accession no. NC_012920.1). SAMtools v.0.1.19-96b5f2294a (34) was used to remove $\mathrm{PCR}$ duplicates and any reads with a mapping quality of $<30$.

\section{Results and discussion}

A summary of the sequencing results is presented in Table 2. We treat the results

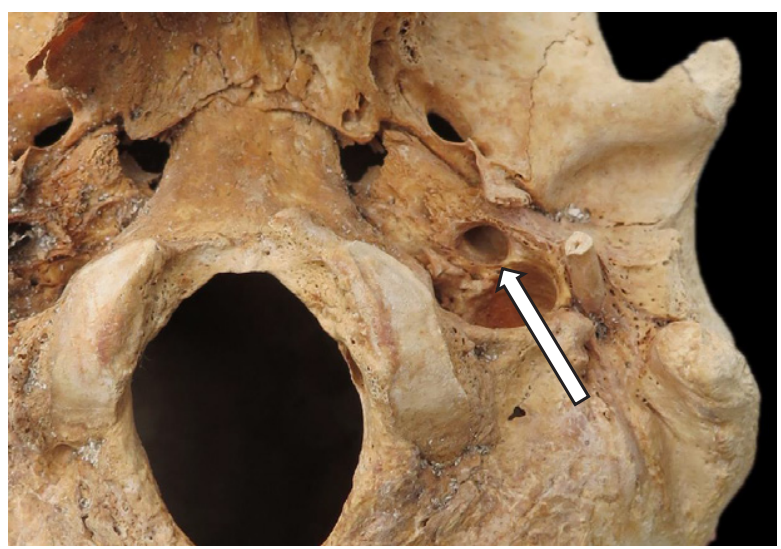

Figure 1. The unnamed ridge (white arrow) separating the carotid canal (anterior) from the jugular foramen (posterior). Photo was taken from the inferior aspect of skull with the anterior facing up.

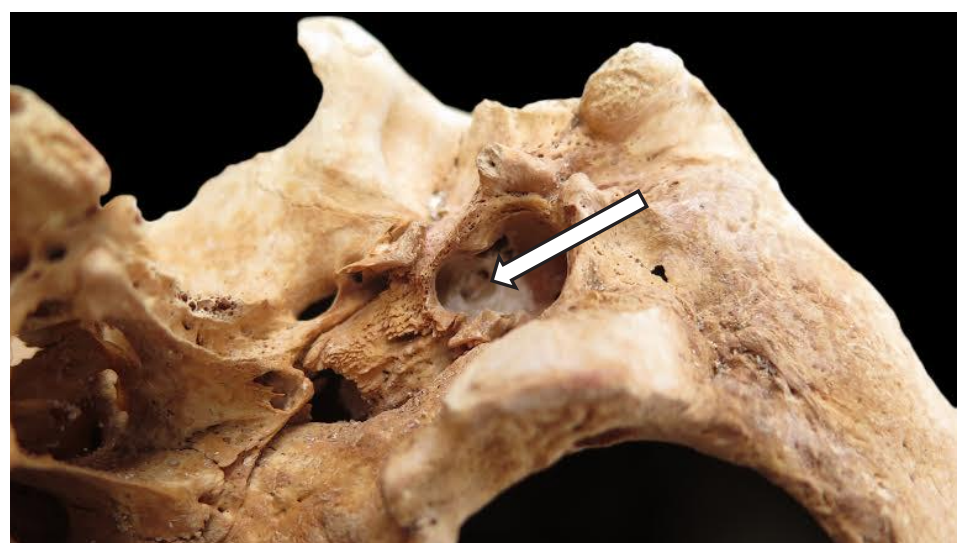

Figure 2. Opening into the osseous labyrinth (white arrow) created with the cranial base drilling method (CBDM). Photo was taken from the inferior aspect of skull with the anterior facing to the left. 
Table 2. Summary of sequencing results.

\begin{tabular}{|c|c|c|c|c|c|c|}
\hline Sample & $\begin{array}{l}\text { Skeletal element } \\
\text { and processing } \\
\text { method }\end{array}$ & $\begin{array}{l}\text { Total } \\
\text { reads }\end{array}$ & $\begin{array}{l}\text { Aligned reads } \\
\text { (After removal } \\
\text { of duplicates) }\end{array}$ & $\begin{array}{c}\text { Endogenous } \\
\text { DNA } \\
\text { yield (\%) }\end{array}$ & $\begin{array}{c}\text { Human copy } \\
\text { number (per mg } \\
\text { bone powder) }\end{array}$ & $\begin{array}{c}\text { Duplicates } \\
\text { (\%) }\end{array}$ \\
\hline \multirow{3}{*}{ BALA36/48 } & Sandblast petrous & 21450126 & 12151418 & 56.65 & $2.41 \mathrm{E}+09$ & 0.02 \\
\hline & CBDM & 19904504 & 6006696 & 30.18 & $4.55 E+08$ & 0.02 \\
\hline & Sandblast postcranial & 17640407 & 721812 & 4.09 & $2.46 \mathrm{E}+07$ & 0.02 \\
\hline \multirow{3}{*}{ BALA118/201 } & Sandblast petrous & 23605587 & 16022105 & 67.87 & $2.94 \mathrm{E}+09$ & 0.02 \\
\hline & CBDM & 16525356 & 3589650 & 21.72 & $1.44 \mathrm{E}+08$ & 0.03 \\
\hline & Sandblast postcranial & 18479101 & 7593 & 0.04 & $3.45 \mathrm{E}+06$ & 0.01 \\
\hline \multirow{3}{*}{ Ecser223 } & Sandblast petrous & 28290826 & 19983191 & 70.63 & $3.56 \mathrm{E}+09$ & 0.02 \\
\hline & CBDM & 15801177 & 6439671 & 40.75 & $4.27 \mathrm{E}+08$ & 0.03 \\
\hline & Sandblast postcranial & 18573422 & 55340 & 0.30 & $8.48 E+06$ & 0.02 \\
\hline \multirow{3}{*}{ Ecser3318 } & Sandblast petrous & 20082351 & 14525293 & 72.33 & $1.58 \mathrm{E}+09$ & 0.02 \\
\hline & CBDM & 16927826 & 9500105 & 56.12 & 1.17E+09 & 0.03 \\
\hline & Sandblast postcranial & 15903195 & 192432 & 1.21 & $1.02 \mathrm{E}+07$ & 0.02 \\
\hline \multirow{3}{*}{ OFE194/442 } & Sandblast petrous & 17461944 & 3162075 & 18.11 & $4.01 \mathrm{E}+08$ & 0.02 \\
\hline & CBDM & 19595560 & 1685180 & 8.60 & $3.07 \mathrm{E}+07$ & 0.03 \\
\hline & Sandblast postcranial & \begin{tabular}{|l|}
18148779 \\
\end{tabular} & 142820 & 0.79 & $3.59 \mathrm{E}+06$ & 0.03 \\
\hline \multirow{3}{*}{ OFE194/443 } & CBDM & 17893892 & 8442926 & 47.18 & 1.23E+09 & 0.02 \\
\hline & CBDM & 9256342 & 4171087 & 45.06 & $1.15 \mathrm{E}+09$ & 0.02 \\
\hline & Sandblast postcranial & 17432281 & 19140 & 0.11 & $6.17 \mathrm{E}+05$ & 0.03 \\
\hline \multirow{3}{*}{ KIS2O4 } & Sandblast petrous & 17428513 & 11647645 & 66.83 & $1.37 \mathrm{E}+09$ & 0.02 \\
\hline & CBDM & 16443023 & 8673484 & 52.75 & $6.81 \mathrm{E}+08$ & 0.03 \\
\hline & Sandblast postcranial & 12622782 & 652428 & 5.17 & $1.58 \mathrm{E}+07$ & 0.03 \\
\hline
\end{tabular}

Table 3. Comparison of the quantitative changes associated with bone processing method and skeletal element.

\begin{tabular}{|c|c|c|c|c|}
\hline Sample & $\begin{array}{l}\text { Skeletal element and } \\
\text { processing method }\end{array}$ & $\begin{array}{l}\text { Fold change: } \\
\text { aligned reads }\end{array}$ & $\begin{array}{l}\text { Fold change: } \\
\text { endogenous yield }\end{array}$ & $\begin{array}{l}\text { Fold change: human copy } \\
\text { number (per mg bone powder) }\end{array}$ \\
\hline \multirow{3}{*}{ BALA36/48 } & Sandblast petrous & - & - & - \\
\hline & CBDM & 1.0-fold reduction & 0.7 -fold reduction & 4.3-fold reduction \\
\hline & Sandblast postcranial & 15.8-fold reduction & 12.9-fold reduction & 96.7-fold reduction \\
\hline \multirow{3}{*}{ BALA118/201 } & Sandblast petrous & - & - & - \\
\hline & CBDM & 3.5-fold reduction & 2.1-fold reduction & 19.3-fold reduction \\
\hline & Sandblast postcranial & 2109-fold reduction & 1696-fold reduction & 849-fold reduction \\
\hline \multirow{3}{*}{ Ecser223 } & Sandblast petrous & - & - & - \\
\hline & CBDM & 2.1-fold reduction & 0.7 -fold reduction & 7.3-fold reduction \\
\hline & Sandblast postcranial & 360-fold reduction & 234-fold reduction & 419-fold reduction \\
\hline \multirow{3}{*}{ Ecser3318 } & Sandblast petrous & - & - & - \\
\hline & CBDM & 0.5 -fold reduction & 0.3 -fold reduction & 0.3 -fold reduction \\
\hline & Sandblast postcranial & 74.5-fold reduction & 58.8-fold reduction & 154-fold reduction \\
\hline \multirow{3}{*}{ OFE194/442 } & Sandblast petrous & - & - & - \\
\hline & CBDM & 0.9 -fold reduction & 1.1-fold reduction & 12.1-fold reduction \\
\hline & Sandblast postcranial & 10.8-fold reduction & 21.9-fold reduction & 111-fold reduction \\
\hline \multirow{3}{*}{ OFE194/443 } & Sandblast petrous & - & - & - \\
\hline & CBDM & 1.0-fold reduction & 0.04-fold reduction & 0.1 -fold reduction \\
\hline & Sandblast postcranial & 434-fold reduction & 428-fold reduction & 1987-fold reduction \\
\hline \multirow{3}{*}{ KIS2O4 } & Sandblast petrous & - & - & - \\
\hline & CBDM & 0.3-fold reduction & 0.3-fold reduction & 1.0-fold reduction \\
\hline & Sandblast postcranial & 16.9-fold reduction & 11.9-fold reduction & 85.5-fold reduction \\
\hline
\end{tabular}

from the complete petrous bone processed with a sandblaster in a cleanroom (sandblast petrous) as the baseline for all comparisons. Comparison of the aligned reads, endogenous DNA content, and human copynumber normalized-per-milligram bone powder suggests that there are quantitative differences in DNA yield that result from both the processing method and the type of bone used. We see little to no difference in the number of duplicate molecules between these processing methods or bone elements, with all duplication rates ranging from $0.2 \%-0.3 \%$.

To compare the magnitude of quantitative differences in bone yield, we calculated fold change in aligned reads, endogenous yield, and normalized human copy number. These results are presented in Table 3. We first compared the data recovered from a complete petrous bone processed with a sandblaster in a cleanroom to that recovered from a petrous bone processed on-site with the CBDM. We find that the CBDM reduced the number of reads aligned to the human genome, the endogenous DNA recovered, and the quantity of human molecules per milligram bone powder. The decrease in aligned reads ranged from 0.3- to 3.5-fold, with a median decrease of 1 -fold. We see a reduction between 0.04- and 2.1-fold in endogenous DNA yield, with a median reduction of 0.7 -fold. Finally, we note a reduction in human copy number between 0.1- and 19.3-fold, with a median reduction of 4.3-fold. Mann-Whitney tests confirm the significance of these reductions with $P=$ 0.038 for both aligned reads and endogenous DNA percentage and $P=0.01$ for human copy number (Supplementary Tables S2-S4). These data suggest that the highest quantity of DNA will be recovered if a complete petrous bone is processed inside a cleanroom.

We also compared the data recovered from a complete petrous bone processed with a sandblaster in a cleanroom to that recovered from a postcranial skeletal element processed in the same controlled environment. We found that using a postcranial element reduces the number of reads aligned to the human genome, the yield of endogenous DNA, and the quantity of human molecules per milligram bone powder far more than use of the CBDM. When compared with a petrous bone processed in a cleanroom, the use of a non-petrous element results in a 10.8- to 2109-fold reduction in aligned reads with a median reduction of 74.5-fold. Similarly, we observe a 11.9- to 1696-fold reduction in endogenous DNA yield (median reduction of 58.8-fold) and an 85.5- to 1987-fold reduction in human copy number (median reduction of 154-fold). The significant reduction in the above values is again confirmed by MannWhitney tests, with $P$-values < 0.001 (Supplementary Tables S2-S4). Thus, while the CBDM yields a reduced quantity of endogenous DNA when compared with processing a complete petrous inside a cleanroom, the above data suggest that the CBDM is superior to the use of a non-petrous postcranial element. Given these results, it is clear that if access to an isolated petrous bone is not possible, the CBDM is decidedly preferable to the use of a postcranial skeletal element.

In addition to a quantitative comparison of the data generated, we also compared nuclear and mitochondrial genomic coverage (Table 4). Coverage of the nuclear genome ranged $0.05 \times-0.37 \times$ for the cleanroomprocessed petrous bone, $0.03 x-0.17 \times$ for the CBDM petrous, and $0.0001 \times-0.01 \times$ for 
the postcranial element. Here, we saw a large improvement when a petrous was used in comparison to a non-petrous element, regardless of the processing method. While the CBDM resulted in a reduction in nuclear genomic coverage ranging from 0.4- to 3.1-fold, we saw a remarkably higher reduction when a postcranial element was used, ranging 16.7- to 2899-fold. This is reflected in the results of Mann-Whitney tests (Supplementary Table S5). Although all pairwise comparisons return significant differences, non-petrous elements differed greatly from petrous data $(P<0.001$ and $P<$ 0.002 for cleanroom processing and CBDM, respectively). Although still significant, the difference between both petrous-processing methods was subtler $(P=0.041)$.

Coverage of the mitochondrial genome parallels this pattern. While the reductions in coverage of the mitochondrial genome when the CBDM is implemented ranged 0.3- to 4.2-fold (with 1 sample showing an increase associated with the CBDM), we note far greater reductions in coverage when a non-petrous element is used, ranging from 12.3- to 3349-fold. Mann-Whitney $P$-values are $<0.001$ in the comparisons of both petrous processing methods with non-petrous elements (Supplementary Table S6). Conversely, no statistical significance is detected between petrous processing methods $(P=0.073)$. The reduction in data associated with the postcranial element often precludes the estimation of mitochondrial haplogroup. We estimate mitochondrial haplogroup for each sample when using the petrous bone (regardless of processing method); however, we were only able to estimate haplogroup in three out of seven cases when a postcranial element was used. Full mitochondrial haplogroup information can be found in Supplementary Table S9.

We provide a new method that is optimal for obtaining skeletal material from the osseous labyrinth of the petrous bone without impacting cranial features critical to the morphometric analysis of cranial shape/ size. As most anthropologists, archaeologists, and museum curators are reluctant to permit destructive sampling of complete skulls, much important ancient skeletal material has remained unanalyzed or has been studied using postcranial elements that compromise the resulting data. Here, we show that postcranial elements are a poor substitute for the petrous bone. While we recognize a reduction in the quantity of DNA obtained when using the CBDM in comparison to tradi-

Table 4. Comparison of nuclear and mitochondrial genomic coverage.

\begin{tabular}{|c|c|c|c|c|c|}
\hline Sample & $\begin{array}{c}\text { Skeletal element and } \\
\text { processing method }\end{array}$ & $\begin{array}{c}\text { Nuclear genome } \\
\text { coverage }\end{array}$ & $\begin{array}{l}\text { Fold change: nuclear } \\
\text { genome coverage }\end{array}$ & $\begin{array}{c}\text { mtDNA } \\
\text { coverage }\end{array}$ & $\begin{array}{l}\text { Fold change: } \\
\text { mtDNA coverage }\end{array}$ \\
\hline \multirow{3}{*}{ BALA36/48 } & Sandblast petrous & $0.22 x$ & - & $11.7 \times$ & - \\
\hline & CBDM & $0.11 \times$ & 1.0-fold reduction & $5.2 x$ & 1.3-fold reduction \\
\hline & Sandblast postcranial & $0.01 \times$ & 21.0-fold reduction & $0.3 x$ & 38.0-fold reduction \\
\hline \multirow{3}{*}{ BALA118/201 } & Sandblast petrous & $0.29 x$ & - & $13.4 \times$ & - \\
\hline & CBDM & $0.07 \times$ & 3.1-fold reduction & $2.6 x$ & 4.2-fold reduction \\
\hline & Sandblast postcranial & $0.0001 \times$ & 2899-fold reduction & $0.004 x$ & 3349-fold reduction \\
\hline \multirow{3}{*}{ Ecser223 } & Sandblast petrous & $0.37 x$ & - & $17.3 x$ & - \\
\hline & CBDM & $0.11 \times$ & 2.4-fold reduction & $8.4 \times$ & 1.1-fold reduction \\
\hline & Sandblast postcranial & $0.0009 x$ & 410-fold reduction & $0.10 x$ & 172-fold reduction \\
\hline \multirow{3}{*}{ Ecser3318 } & Sandblast petrous & $0.27 \times$ & - & $14.5 x$ & - \\
\hline & CBDM & $0.17 \times$ & 0.6-fold reduction & $10.9 x$ & 0.3-fold reduction \\
\hline & Sandblast postcranial & $0.003 x$ & 89.0-fold reduction & $0.9 \times$ & 15.1-fold reduction \\
\hline \multirow{3}{*}{ OFE194/442 } & Sandblast petrous & $0.05 x$ & - & $3.9 \times$ & - \\
\hline & CBDM & $0.03 x$ & 0.7 -fold reduction & $1.4 \times$ & 1.8-fold reduction \\
\hline & Sandblast postcranial & $0.002 x$ & 24.0-fold reduction & $0.09 x$ & 42.3-fold reduction \\
\hline \multirow{3}{*}{ OFE194/443 } & Sandblast petrous & $0.15 x$ & - & $10.0 x$ & - \\
\hline & CBDM & $0.08 x$ & 0.9-fold reduction & $5.1 \times$ & 1.0-fold reduction \\
\hline & Sandblast postcranial & $0.0002 x$ & 749-fold reduction & $0.05 x$ & 199-fold reduction \\
\hline \multirow{3}{*}{ KIS204 } & Sandblast petrous & $0.2228 x$ & - & $13.3 x$ & - \\
\hline & CBDM & $0.1622 x$ & 0.4-fold reduction & $13.7 \times$ & 0.03-fold increase \\
\hline & Sandblast postcranial & $0.0126 x$ & 16.7-fold reduction & $1.0 x$ & 12.3-fold reduction \\
\hline
\end{tabular}

tional methods of petrous bone processing, the reduction is relatively small in comparison to the reduction associated with the use of a non-petrous element.

Despite these encouraging results, the use of the CBDM to process a sample should be decided on a case-by-case basis. When DNA preservation is expected to be poor, the destructive extraction of the osseous labyrinth in a cleanroom may maximize chances of successful results. However, for specimens that are expected to be well-preserved on a molecular level, such as those excavated from cold or temperate climates, we recommend the CBDM. In these situations, it is likely that the CBDM will yield workable data and preserve the structure of the skull for anthropological analyses. In contrast, use of a non-petrous element is likely to yield less data than required for genetic analysis, even in well-preserved samples.

It is likely that future work will further improve the CBDM. An improvement in the quality of the bone powder obtained using the CBDM may reduce the amount of exogenous material, primarily sediment and environmental material from the burial environment, mixed into the bone powder collected from the osseous labyrinth that likely results in the observed reduction in endogenous DNA content. We suggest the future implementation of additional steps before DNA extraction occurs, potentially resulting in downstream improvements in the quantity of DNA recovered from these specimens.
For example, a sieving or 'pre-digestion' step $(21,22)$ may assist in the removal of soil and other environmental material, which may improve both quantity and quality of DNA yield in future specimens. We demonstrate that the CBDM provides another tool for the multidisciplinary study of ancient human remains. Going forward, combining craniometric and genetic studies of complete skulls will bring us one step closer to improved multidisciplinary reconstructions of the past.

\section{Author contributions}

R.Pi., K.S., D.F., and M.N. conceptualized and designed the experiment. T.B., Z.B., A.C., J.D., J.Z.G., G.K-B., I.K., O.L., I.P., R.Pa., Z.P., G.S., T.S., and T.H. provided samples, performed archaeological and physical anthropological assessment, provided archaeological and anthropological background, and contributed the archaeological context for the Supplementary Material. K.S., D.F., O.C., M.N., B.G., T.H., and T.S. performed the experiments. D.F. and K.S. analyzed the raw sequencing data. O.C. conducted the statistical analyses. K.S. wrote the manuscript with input from all authors.

\section{Acknowledgments}

We thank David Reich, Nadin Rohland and Kristin Stewardson for helpful input on the manuscript, Nadin Rohland and Catherine Moss for their assistance with qPCR, and Pontus Skoglund for providing access to 
the calico software. K.S. was supported by NSF grant BCS-1613577; D.F. was supported by IRC Post-Graduate grant GOIPG/2013/36; M.N. was supported by IRC Postdoctoral grant (GOIPD/2013/1); B.G. was supported by H2020-MSCAIF-2015 (703373); T.H. was supported by the János Bolyai Research Fellowship of the Hungarian Academy of Sciences (BO/00094/15/8); R.Pi. was supported by ERC starting grant ADNABIOARC (263441).

\section{Competing interests}

The authors declare no competing interests.

\section{References}

1. Lazaridis, I., N. Patterson, A. Mittnik, G. Renaud, S. Mallick, K. Kirsanow, P.H. Sudmant, J.G. Schraiber, et al. 2014. Ancient human genomes suggest three ancestral populations for present-day Europeans. Nature 513:409-413.

2. Lazaridis, I., D. Nadel, G. Rollefson, D.C. Merrett, N. Rohland, S. Mallick, D. Fernandes, M. Novak, et al. 2016. Genomic insights into the origin of farming in the ancient Near East. Nature 536:419-424.

3. Allentoft, M.E., M. Sikora, K.-G. Sjögren, S. Rasmussen, M. Rasmussen, J. Stenderup, P.B. Damgaard, H. Schroeder, et al. 2015. Population genomics of Bronze Age Eurasia. Nature 522:167172.

4. Jones, E.R., G. Gonzalez-Fortes, S. Connell, V. Siska, A. Eriksson, R. Martiniano, R.L. McLaughlin, M.G. Llorente, et al. 2015. Upper Palaeolithic genomes reveal deep roots of modern Eurasians. Nat. Commun. 6:8912.

5. Mathieson, I., I. Lazaridis, N. Rohland, S. Mallick, N. Patterson, S.A. Roodenberg, E. Harney, K. Stewardson, et al. 2015. Genome-wide patterns of selection in 230 ancient Eurasians. Nature 528:499503.

6. Martiniano, R., A. Caffell, M. Holst, K. HunterMann, J. Montgomery, G. Müldner, R.L. McLaughlin, M.D. Teasdale, et al. 2016. Genomic signals of migration and continuity in Britain before the Anglo-Saxons. Nat. Commun. 7:10326.

7. Skoglund, P., C. Posth, K. Sirak, M. Spriggs, F. Valentin, S. Bedford, G.R. Clark, C. Reepmeyer, et al. 2016. Genomic insights into the peopling of the Southwest Pacific. Nature 538:510-513.

8. Leonardi, M., P. Librado, C. Der Sarkissian, M. Schubert, A.H. Alfarhan, S.A. Alquarishi, K.A.S. Al-Rasheid, C. Gamba, et al. 2016. Evolutionary Patterns and Processes: Lessons from Ancient DNA. Syst. Biol. pii:syw059.

9. Der Sarkissian, C., M.E. Allentoft, M.C. ÁvilaArcos, R. Barnett, P.F. Campos, E. Cappellini, L. Ermini, R. Fernández, et al. 2015. Ancient genomics. Philos. Trans. R. Soc. Lond. B Biol. Sci. 370:20130387.

10. Slatkin, M. and F. Racimo. 2016. Ancient DNA and human history. Proc. Natl. Acad. Sci. USA 113:63806387.

11. Dabney, J., M. Knapp, I. Glocke, M.-T. Gansauge, A. Weihmann, B. Nickel, C. Valdiosera, N. García, et al. 2013. Complete mitochondrial genome sequence of a Middle Pleistocene cave bear reconstructed from ultrashort DNA fragments. Proc. Natl. Acad. Sci. USA 110:15758-15763.
12. Gansauge, M.-T. and M. Meyer. 2013. Singlestranded DNA library preparation for the sequencing of ancient or damaged DNA. Nat. Protoc. 8:737-748.

13. Rohland, N., E. Harney, S. Mallick, S. Nordenfelt, and D. Reich. 2015. Partial uracil-DNA-glycosylase treatment for screening of ancient DNA. Philos. Trans. R. Soc. Lond. B Biol. Sci. 370:20130624.

14. Cruz-Dávalos, D.I., B. Llamas, C. Gaunitz, A. Fages, C. Gamba, J. Soubrier, P. Librado, A. Seguin-Orlando, et al. 2017. Experimental conditions improving in-solution target enrichment for ancient DNA. Mol Ecol Resour._17:508-522.

15. Fu, Q., C. Posth, M. Hajdinjak, M. Petr, S. Mallick, D. Fernandes, A. Furtwängler, W. Haak, et al. 2016. The genetic history of Ice Age Europe. Nature 534:200-205

16. Fernández, E., A. Pérez-Pérez, C. Gamba, E. Prats, P. Cuesta, J. Anfruns, M. Molist, E. ArroyoPardo, and D. Turbón. 2014. Ancient DNA analysis of 8000 BC Near Eastern farmers supports an Early Neolithic pioneer maritime colonization of Mainland Europe through Cyprus and the Aegean Islands. PLoS Genet. 10:e1004401.

17. Gallego Llorente, M., E.R. Jones, A. Eriksson, V. Siska, K.W. Arthur, J.W. Arthur, M.C. Curtis, J.T Stock, et al. 2015. Ancient Ethiopian genome reveals extensive Eurasian admixture throughout the African continent. Science 350:820-822

18. Broushaki, F., M.G. Thomas, V. Link, S. López, L. van Dorp, K. Kirsanow, Z. Hofmanová, Y. Diekmann, et al. 2016. Early Neolithic genomes from the eastern Fertile Crescent. Science 353:499-503.

19. Gallego Llorente, M., S. Connell, E.R. Jones, D.C. Merrett, Y. Jeon, A. Eriksson, V. Siska, C. Gamba, et al. 2016. The genetics of an early Neolithic pastoralist from the Zagros, Iran. Sci. Rep. 6:31326.

20. Gamba, C., E.R. Jones, M.D. Teasdale, R.L. McLaughlin, G. Gonzalez-Fortes, V. Mattiangeli, L. Domboroczki, I. Kovari, et al. 2014. Genome flux and stasis in a five millennium transect of European prehistory. Nat. Commun. 5:5257.

21. Hansen, H.B., P.B. Damgaard, A. Margaryan, J. Stenderup, N. Lynnerup, E. Willerslev, and M.E. Allentoft. 2017. Comparing Ancient DNA Preservation in Petrous Bone and Tooth Cementum. PLoS One 12:e0170940

22. Damgaard, P.B., A. Margaryan, H. Schroeder, L. Orlando, E. Willerslev, and M. Allentoft. 2015 Improving access to endogenous DNA in ancient bones and teeth. Sci. Rep. 5:11184

23. Korlevic, P., T. Gerber, M.-T. Gansauge, M. Hajdinjak, S. Nagel, A. Aximu-Petri, and M. Meyer. 2015. Reducing microbial and human contamination in DNA extractions from ancient bones and teeth. BioTechniques 59:87-93.
24. Rasmussen, M., Y. Li, S. Lindgreen, J.S. Pedersen, A. Albrechtsen, I. Moltke, M. Metspalu, E. Metspalu, et al. 2010. Ancient human genome sequence of an extinct Palaeo-Eskimo. Nature 463:757-762.

25. Pinhasi, R., D. Fernandes, K. Sirak, M. Novak, S. Connell, S. Alpaslan-Roodenberg, F. Gerritsen, V. Moiseyev, et al. 2015. Optimal Ancient DNA Yields from the Inner Ear Part of the Human Petrous Bone. PLoS One 10:e0129102.

26. Ekdale, E.G. 2013. Comparative anatomy of the bony labyrinth (inner ear) of placental mammals. PLoS One 8:e66624.

27. Frisch, T., M.S. Sørensen, S. Overgaard, M. Lind, and P. Bretlau. 1998. Volume-Referent Bone Turnover Estimated From the Interlabel Area Fraction After Sequential Labeling. Bone 22:677-682.

28. Frisch, T., S. Overgaard, M.S. Sørensen, and P. Bretlau. 2000. Estimation of volume referent bone turnover in the otic capsule after sequential point labeling. Ann. Otol. Rhinol. Laryngol. 109:33-39.

29. Bloch, S.L. and M.S. Sørensen. 2010. The viability and spatial distribution of osteocytes in the human labyrinthine capsule: a quantitative study using vectorbased studies. Hear. Res. 270:65-70.

30. von Cramon-Taubadel, N. 2014. Evolutionary insights into global patterns of human cranial diversity: population history, climactic, and dietary effects. J. Anthropol. Sci. 92:43-77.

31. Meyer, M. and M. Kircher. 2010. Illumina sequencing library preparation for highly multiplexed target capture and sequencing. Cold Spring Harbor Protocols 2010: pdb.prot5448.

32. Martin, M. 2011. Cutadapt removes adapter sequences from high-throughput sequencing reads. EMBnet.journal 17:10-12.

33. Li, H. and R. Durbin. 2009. Fast and accurate read alignment with Burrows-Wheeler transform. Bioinformatics 25:1754-1760.

34. Li, H., B. Handsaker, A. Wysoker, T. Fennell, J. Ruan, N. Homer, G. Marth, G. Abecasis, and R. Durbin. 2009. The sequence alignment/map format and SAMtools. Bioinformatics 25:2078-2079.

Received 11 January 2017; accepted 17 April 2017.

Address correspondence to Kendra Sirak, Emory University, Department of Anthropology, 1557 Dickey Drive, Atlanta, GA 30322 or Ron Pinhasi, School of Archaeology and Earth Institute, University College Dublin, Belfield, Dublin 4, Ireland. E-mail: kendra.sirak@emory.edu or ron.pinhasi@ucd.ie

To purchase reprints of this article, contact: biotechniques@fosterprinting.com

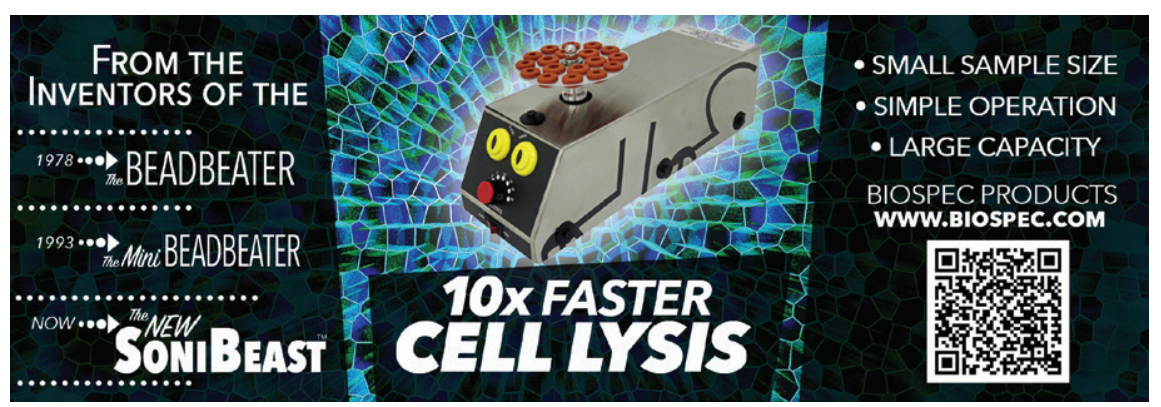

